\title{
Exterior Noise Due to Interaction of Tire- Thermoplastic Transverse Rumble Strips
}

\author{
Zaiton Haron ${ }^{1}$, Mohd Hanifi Othman ${ }^{2, *}$, Khairulzan Yahya ${ }^{1}$, Mohd Rosli Hainin ${ }^{3}$, \\ Kamarudin Ambak ${ }^{2}$, and Nadirah Darus ${ }^{1}$ \\ ${ }^{1}$ Department of Structure and Materials, Faculty of Civil Engineering, Universiti Teknologi Malaysia, \\ 81310 Skudai, Johor, Malaysia \\ ${ }^{2}$ Smart Driving Research Centre (SDRC), Faculty of Civil and Environmental Engineering, Universiti \\ Tun Hussein Onn Malaysia, 86400, Parit Raja, Johor, Malaysia \\ ${ }^{3}$ Department of Geotechnics and Transportation, Faculty of Civil Engineering, Universiti Teknologi \\ Malaysia, 81310 Skudai, Johor, Malaysia
}

\begin{abstract}
Transverse rumble strips (TRS) are a common choice to reduce vehicle speed and increase driver alertness on roadways. However, there is a potential trade-off using them on rural roadway due to the noise problem created when vehicles go over the strips. The present study investigated the noise level, spectral analysis and the possible noise generation mechanism when the TRS hit by a vehicle. Ten-raised-rumbler (RR) and three-layeroverlapped (TLO) were selected in this study as they have received complaints from the public. Results showed that RR generated relatively higher noise and impulse at low speed, and increased sound level in each octave band. Based on these results, RR may irritate human ears even when the vehicle travels at low speed. It was found that RR increased all noise generation mechanism of tire-pavement interaction whilst for the TLO increased structural resonance, sidewall and surface texture vibration.
\end{abstract}

\section{Introduction}

Motor vehicle accidents are the second most frequent cause of death in the entire world. Around 1.2 million people are killed each year on the road and 50 million more are injured [1]. Speeding and careless driving are the two main causes of accidents, contributing 32.8 and 28.2 percent respectively to the total number of accidents in Malaysia [2]. Speeding also contributed to about 30 percent of fatal crashes in the United States [3]. Alternative measures consisting of a road layout and its associated features including transverse rumble strips which are able to subconsciously inform drivers of upcoming road conditions were introduced. Transverse rumble strips (TRS) made of a groove or raised lateral pattern are introduced to reduce vehicle speed and increase driver alertness on the roadway. Generally, TRS around the world are diverse in terms of configuration, dimensions, colour, and profile. TRS is intended to give an audible, visual and tactile cue of when an operational decision point is approaching [4]. TRS vertically deflects the wheels of a vehicle driving over them and produces both noise and vibration [5].

* Corresponding author: hanifi@uthm.edu.my 
As in Malaysia, thermoplastic TRS is one of the most frequently used forms. It is classified as a raised rumble strip and it has a thickness in the range 3-7mm [6]. Thermoplastic TRS are commonly applied as they contribute several factors including a readiness for immediate use, high durability, good retro reflectivity and relatively low cost. In order to increase the visibility through retro reflectivity elements, glass beads are also intermixed into the thermoplastic and partially embedded onto the surface of the marking binder material [7]. Studies of TRS made of thermoplastic have shown that it is able to reduce vehicle speed and road accidents [8]. According to [9], thermoplastic TRS with narrow strips are able to increase the road noise level, LAeq by around $2-4 \mathrm{dBA}$. In addition, TRS noise is claimed to be in the pattern of impulse noise which is the most annoying to people $[9,10]$. Malaysia is a developing country, and is presently suffering from an increase in noise pollution arising from traffic noise. The problem is compounded with TRS which are widely used for reasons of safety, despite the fact many premises are built alongside the roads. Malaysia has also not yet developed a practical policy to cope this situation.

The primary purpose of the present study, therefore, was to assess the characteristics of noise generated by roads with the installation of thermoplastic transverse rumble strips. Two typical TRS profiles widely used in Malaysia were selected and the anticipated noise mechanism generation for the typical TRS were obtained to facilitate the local authorities in the selection of the reliable installation of TRS. This specific characteristic should be given close attention since many premises are located close to the road.

\subsection{Tire-pavement noise generation}

Sound generated by interaction between tire and pavement play a significant role when the vehicle speed exceeding $30 \mathrm{~km} / \mathrm{h}$. according to previous research sound could be generated by the followings mechanisms; tire tread block impact occurred at $600 \mathrm{~Hz}-900 \mathrm{~Hz}$ [11], surface texture impact was dominant at $700 \mathrm{~Hz}-1300 \mathrm{~Hz}$ [12], tire belt/carcass vibration is the dominant mechanism for the frequency around $500 \mathrm{~Hz}$ [13], side wall vibration occurred at a frequency $<1000 \mathrm{~Hz}[11,14]$, and the air pumping mechanism was at a frequency range between $500 \mathrm{~Hz}-3 \mathrm{kHz}$ [15] or above $1 \mathrm{KHz}$ [14].

An adhesion mechanism is produced as the tyre rolls on the surface of the pavement. The release of the block produces tangential or radial vibration and yields a carcass response and side wall vibration. If the tyres hit the contact surface with a high angle of attack compared with the road surface, the tangential and radial vibration become higher. Air pumping occurs when the tread blocks enter the contact patch and trap air between the pavement and tyre which is then compressed and pumped out of the tread block. According to [14], the macrotexture and megatexture of the road surface play significant roles in noise generation. Increases in megatexture to $80 \mathrm{~mm}$ will increase the tyre noise in the low frequency of less than $1 \mathrm{KHz}$ and when the macrotexture increases to $3 \mathrm{~mm}$ the tyre noise in frequency greater than $1 \mathrm{KHz}$ decreases due to air pumping. The megatexture is responsible for radial and tangential vibration of the tyre, which causes the mechanism in low and high frequency ranges.

The authors consider that the interaction of the tire and TRS have similarities with the interaction of the tire and road. Thus, an experimental method was conducted based on the controlled pass by method test procedure, derived from the Coast-By Method $[12,16]$ for the selected sites. 


\section{Materials and methods}

Two sites installed with typical thermoplastic rumble strips were selected. Site 1 was installed with the saw blade pattern or ten-raised-rumbler (RR) profile, and site 2 with the three-layer-overlapped profile (TLO) (Fig. 1).

The Coast-By Method was used as it can directly measure tire-pavement noise from individual vehicles in free-flowing and essentially constant-speed traffic. To avoid the effect of the test vehicle type and the conditions of the test site [12] the same test vehicle was used throughout the experiments at site 1 and site 2 . For each site, the test vehicle was ran on the roadway using four levels of speed of $30 \mathrm{~km} / \mathrm{h}, 50 \mathrm{~km} / \mathrm{h}, 70 \mathrm{~km} / \mathrm{h}$ and $90 \mathrm{~km} / \mathrm{h}$. The specification of each profile can be seen in Fig. 1, and both roads are considered straight in order to meet the requirements of ISO 13325 [16], with the condition of the pavement and TRS surfaces being good and dry.

The test vehicle was a typical passenger car used on the road in Malaysia, which is a 2005 model Perodua Myvi with a weight capacity of $950 \mathrm{~kg}$. This vehicle is classified as a light vehicle since the gross vehicle weight (GVW) is less than $4500 \mathrm{~kg}$. The tire size is $175 / 65 \mathrm{R} 14$. The tire pressure was fixed at $250 \mathrm{kPa}$ for all measurements. A type-1 integrating-averaging Pulsar Model 33 sound level meter was used for the measurement. The sound level meter was calibrated using a Model 105 acoustic calibrator before and after the measurements. The microphone was equipped with a foam windscreen to reduce the effect of wind noise on the data. A multifunctional anemometer was used for measuring the wind speed and air temperature, and an IR thermometer was used to measure TRS and pavement temperature.

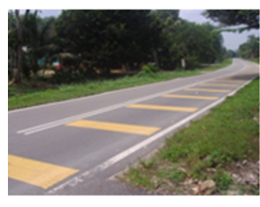

Site 1

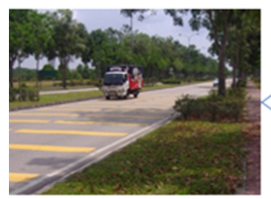

Site 2

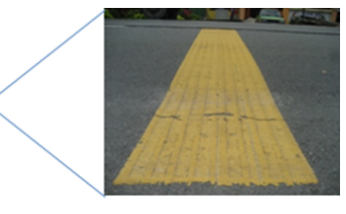

Ten Raised Rumbler (RR) profile

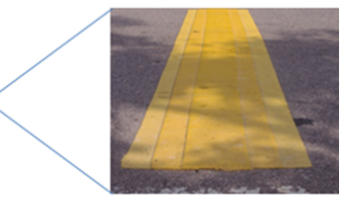

Three layered overlap (TLO) profile

(a) Types of thermoplastic profile and the experimental sites

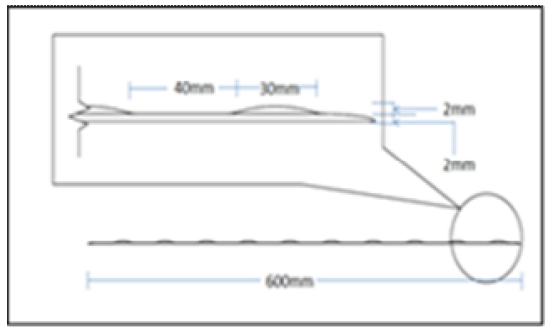

Dimension of RR profile

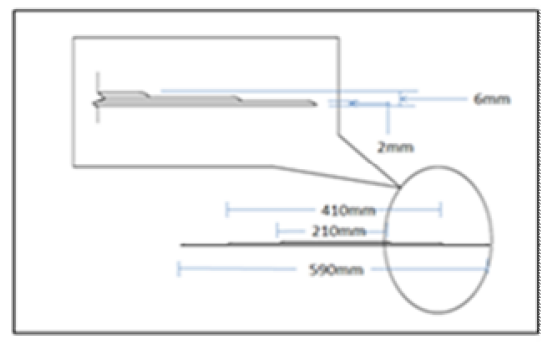

Dimension of TLO profile

(b) Dimensions of profiles

Fig. 1. Profile of thermoplastic TRS and their dimensions 
Each site has two points of measurement (Fig. 2). Point 1 is located in the middle of a set of TRS. At this location the readings were taken 4 times, i.e. once for each speed. At Point 2 the measurements were carried out at $300 \mathrm{~m}$ from Point 1 to avoid the effect of TRS. This position is sufficient because it is larger than the value proposed by the Transportation Association of Canada which states that the noise due to the grooved surface of the TRS will be dissipated at $100 \mathrm{~m}$ [5]. At Point 2 the same experiments were repeated without TRS. The sound level meter was installed at $7.5 \mathrm{~m}$ from the middle of the test lane and the microphone was at a height of $1.5 \mathrm{~m}$. The sound measurements were carried out using fast time weighting (fast) and A-frequency weighting, impulse time weighting (impulse) and A-frequency weighting, and spectral mode analysis of the one-third octave band were measured.

The parameters considered in the comparison between the sound level for the roadway with and without TRS were maximum measured LAFmax, and maximum measured LAImax. LAFmax, and LAImax were the maximum reading when the test car was $7.5 \mathrm{~m}$ from the sound level meter. Readings for wind speed and temperature of the air, TRS and pavement surface were taken before and after the measurements. Surface temperature correction was applied for every reading, as required by ISO 13325 [16]. LAFmax and LAImax were then corrected using Equation 1 to obtain LAF and LAI, and instead of pavement, in this study TRS temperature was taken as the surface temperature. To avoid external noise from other vehicles that can lead to data bias, the measurement process was carried out between 12:00am and 3:00 am.

$$
\mathrm{LAF}=\mathrm{LAFmax}+\mathrm{K}(20-\mathrm{t})
$$

where: $\mathrm{LAF}=$ is the corrected measured LAFmax, $\mathrm{K}=$ is the coefficient equal to $-0.03 \mathrm{~dB}$ (A-weighted) $/{ }^{\circ} \mathrm{C}$ when the measured test surface temperature is $>20^{\circ} \mathrm{C}$ and $-0.06 \mathrm{~dB}$ (Aweighted $) /{ }^{\circ} \mathrm{C}$ when the measured test surface temperature is less than $20^{\circ} \mathrm{C}, \mathrm{t}=$ surface temperature

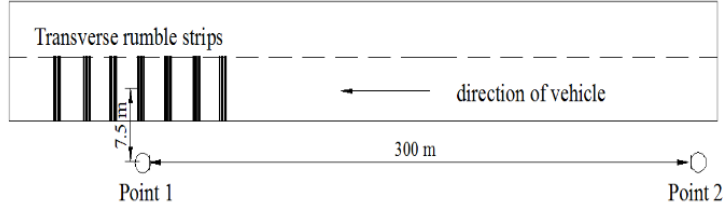

Fig. 2. Location of the sound level meter

The spectrum analysis for when the TRS was hit by vehicles were analysed and compared with previous findings from tire/road interaction frequency spectra analysis conducted by Kim et al. [11], Sandberg and Ejsmont [12], Keulen and Duškov [15] and Wayson [14].

\section{Results and analysis}

\subsection{Relationship between sound level and vehicle speed}

Fig. 3 presents the variation in maximum LAF generated when a vehicle hit RR and TLO, in comparison with and without TRS. Generally, for both RR and TLO profiles, it was clearly observed that faster vehicle speeds generate a higher noise. The sound pressure levels have been corrected based on the TRS surface temperature using Equation 1 as the pavement, and the TRS temperatures were $29.2^{\circ} \mathrm{C}$ and $29.6^{\circ} \mathrm{C}$, respectively, at site 1 and $30.3^{\circ} \mathrm{C}$ and $31.3^{\circ} \mathrm{C}$, respectively, at site 2 . Both locations had the same background noise 
level (45 dBA). The readings were valid as air temperatures were within $5^{\circ} \mathrm{C}$ to $40^{\circ} \mathrm{C}$ and the measured wind speed at the microphone height was less than $5 \mathrm{~m} / \mathrm{s}$, as recommended by ISO 13325 [16] to avoid sound refraction that will affect the readings [17].

Fig. 4 shows in detail the increment in noise level with and without both of the TRS profiles and a comparison between these profiles. It is seen that RR increased in noise level by $2.4 \mathrm{~dB}(\mathrm{~A})(3.8 \%)$, while TLO only increased by $0.9 \mathrm{~dB}(\mathrm{~A})(3.2 \%)$ for the single vehicle speed of $30 \mathrm{~km} / \mathrm{h}$. At a vehicle speed of $50 \mathrm{~km} / \mathrm{h}$ the RR profiles exhibited a similar trend with a higher increase in noise level. However at $70 \mathrm{~km} / \mathrm{h}$ the TLO exhibits a higher increase than RR of $4.5 \mathrm{~dB}(\mathrm{~A})(5.7 \%)$, and at a vehicle speed of $90 \mathrm{~km} / \mathrm{h}$, both profiles generated a similar increase. This finding shows that the $\mathrm{RR}$ is able to produce a just noticeable difference at $70 \mathrm{~km} / \mathrm{h}$ and $90 \mathrm{~km} / \mathrm{h}$. Thus the installation of RR or TLO is able to exhibit noise changes that can be detected by the local residents near the roadway.

Fig. 5 presents a comparison between the LAF and LAI generated from the road installed with either profile. It can be clearly seen that LAI for each speed and each profile exhibit a higher sound pressure level. The increase in Fig. 6 shows the (LAI-LAF) values for RR of $3 \mathrm{dBA}$ for a speed $70 \mathrm{~km} / \mathrm{h}$ and below and reduce afterwards. However the trend for the TLO fluctuates. This result indicates that the noise has an impulsive character. In comparison with the road without RR and TLO, the (LAI-LAF) has differences of up to 1 $\mathrm{dBA}$. This finding shows that the thermoplastic RR and TLO are similar with to pavement groove types of TRS and roads with metal cleats [18,19].

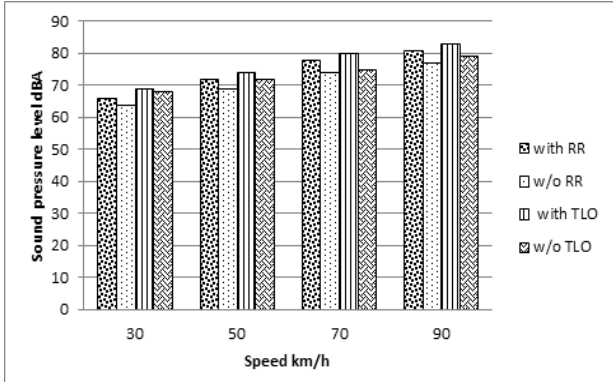

Fig. 3. LAF generated by roads installed with and without RR and a road installed with and without TLO

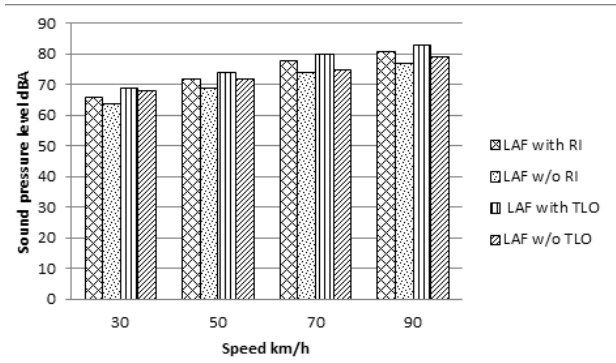

Fig.5. LAF and LAI generated by roads installed with and without RR and road installed with and without TLO

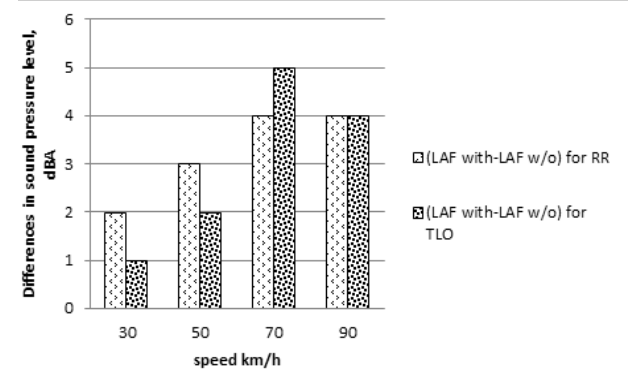

Fig. 4. Differences in LAF between roads installed with and without RR and road installed with and without TLO

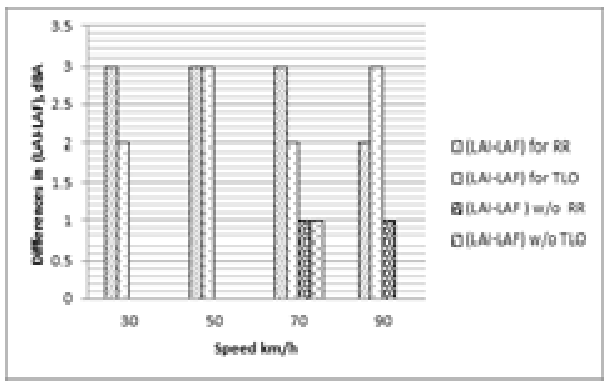

Fig. 6. The determination of the impulsive character 


\subsection{Frequency spectrum analysis and anticipated tire-TRS mechanism of noise generation}

The frequency spectrum of noise at the moment the tire hits the RR and TLO can be seen in Fig. 7(a-d) and Fig. 8(a-d), respectively. This reading was the maximum reading when the test car was $7.5 \mathrm{~m}$ from the sound level meter. The RR profile tends to have a more uniform increase in all of the frequencies. The anticipated mechanism was air pumping, side wall vibration, and surface and tire impact. Air pumping as a result of the findings of Keulen and Duškov [15] was dominant for the frequency range between 1-3kHz. Air pumping occurs when the tire is rolling and a volume of air is enclosed in the contact patch within the grooved line between the raised lines and pores constituted by the tread pattern grooves and the surface texture. Air is compressed and pressed away at the front of the contact patch and expanded and sucked into the cavities at the rear. The variations in surface texture and tread pattern grooves, the latter of which will be rapidly squeezed, produce variations in air flow over time. This generates vibrations in the surrounding air and therefore constitutes a source of sound.

Alternatively, sidewall vibration, surface and texture tread block, according to Kim et al. [11] and Sandberg and Ejsmont [12] were found for frequencies less than $1000 \mathrm{~Hz}, 700$ $1300 \mathrm{~Hz}$ and $600-900 \mathrm{~Hz}$, respectively. Side wall vibration is caused by a collision between the tread blocks and TRS. As the tire interacts with the macro-texture of the RR $(2 \mathrm{~mm})$, the tread vibrations are transported to the side wall which acts as a 'sounding board' and radiates sound. Surface texture impact is generated when the tire tread enters the contact zone at certain angles relative to the road, the tire tread displacement itself contains a radial and tangential component. TRS with a macro-texture of $2 \mathrm{~mm}$ gives a higher attack angle and generates more gradual displacement. Tire tread impact is represented by the radial vibration which is the sudden displacement of tread element, in relation to its original position in the rotating tire, when it impacts on the TRS surface. This may explain why the ten-raised-rumbler profile produced a more uniform increment in sound level for each frequency since it was dominated by these three mechanisms. In addition, the RR profile has a relatively high height of unevenness $(2 \mathrm{~mm})$, width $(30 \mathrm{~mm})$ and spacing $(40 \mathrm{~mm})$. The asperity height unevenness and the asperity spacing are defined as important parameters that govern tire vibration noise.

On the other hand, the generation of noise from TLO is governed by structural resonance, surface texture vibration, and side wall vibration. In Fig. 8, TLO tends to have a significant increase in sound level at low frequencies below $315 \mathrm{~Hz}$. Based on the finding by Bolton and Kwon [13], structural resonance (Fig. 9) is the dominant mechanism at low frequencies. Structural resonance is represented by tire belt/carcass vibration [12]. The overall thickness of the TLO is relatively thick at $6 \mathrm{~mm}$ which may be a key factor to this type of mechanism. However, according to Perisse [19], the increment in sound level occurs at a higher frequency as the speed is increased. This can be seen in Fig. 8(c) and (d) for a vehicle speed of $70 \mathrm{~km} / \mathrm{h}$ and $90 \mathrm{~km} / \mathrm{h}$. TLO also induced more dominant surface texture vibrations, which is combination of radial (Fig. 10) and tangential vibration (Fig. 11) [12]. Frequency is quite dominant in the $250 \mathrm{~Hz}$ to $2 \mathrm{kHz}$ range at speeds of $70 \mathrm{~km} / \mathrm{h}$ and $90 \mathrm{~km} / \mathrm{h}$, which may be due to this mechanism since Sandberg and Ejsmont [12] state that this mechanism is dominant at $700-1300 \mathrm{~Hz}$. Sidewall vibration involve dominant frequency $<1000 \mathrm{kHz}$ [11]. Sidewall vibration (Fig. 12) induces collision between the tread blocks and the road [15], and in this case the tread block and TRS. As the TLO is relatively thick the collision becomes stronger and results in higher sound pressure levels for frequencies of less than $1000 \mathrm{~Hz}$. 


\subsection{Effect of TRS on noise exposure}

From the above findings, it is notable that TRS increase the noise level by up to $5 \mathrm{dBA}$, and both profiles have impulsive characteristics. Furthermore, although TRS increases the noise level by a relatively small amount, their psychological impact may be greater because of the impulsive impact. In the work of Bendtsen et al. [9], TRS generated impulsive and suggested that a $5 \mathrm{~dB}$ penalty for impulsive noise in order to predict the community response. The saw blade pattern or RR increases the sound pressure level at high frequency ( 1 to $4 \mathrm{KHz}$ ) which enable the human ear most sensitive with while the TLO mainly increases the sound pressure level in the low frequency which cannot be heard by the human ear. Thus, based on the impulsive nature and frequency spectral analysis, it is recommended that the saw blade pattern or RR can only be installed on roads that are located away from sensitive premises.

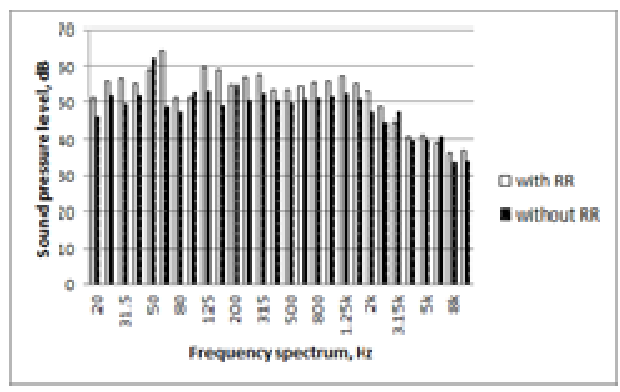

(a) $30 \mathrm{~km} / \mathrm{h}$

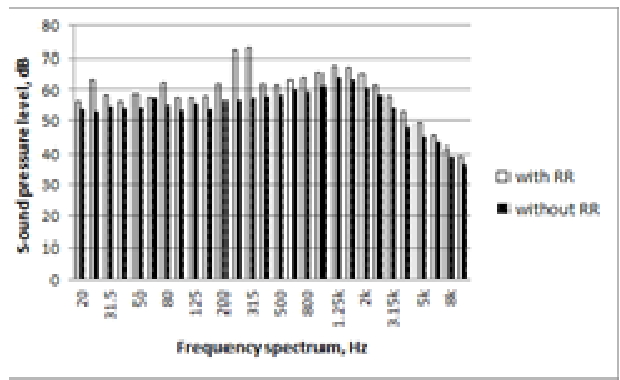

(c) $70 \mathrm{~km} / \mathrm{h}$

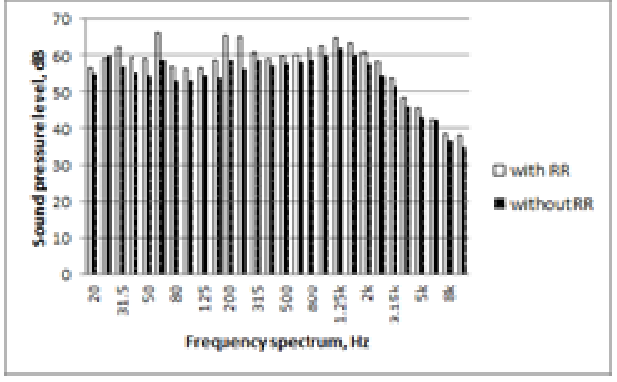

(b) $50 \mathrm{~km} / \mathrm{h}$

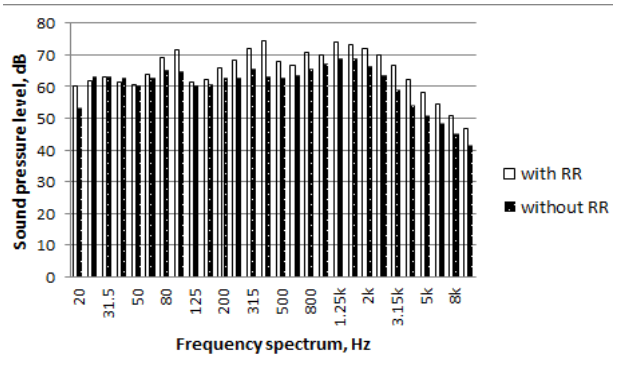

(d) $90 \mathrm{~km} / \mathrm{h}$

Fig. 7. Spectral frequency analysis of each vehicle's speed for roads with and without RR

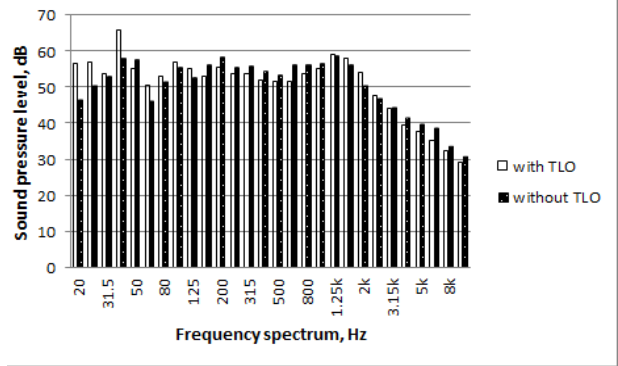

(a) $30 \mathrm{~km} / \mathrm{h}$

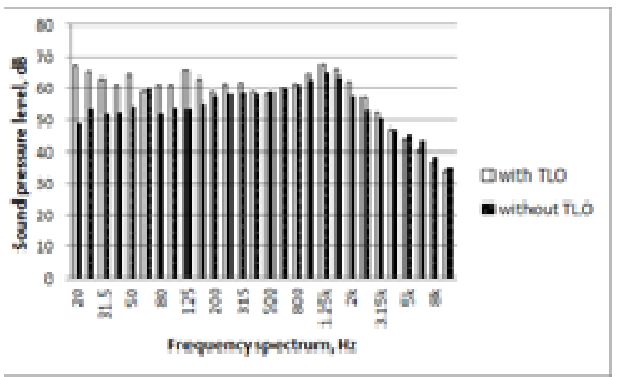

(b) $50 \mathrm{~km} / \mathrm{h}$ 


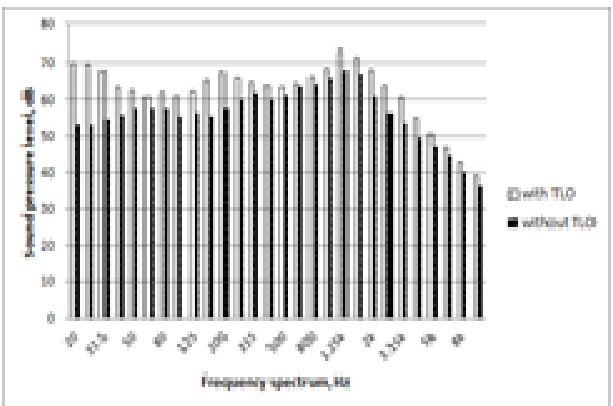

(c) $70 \mathrm{~km} / \mathrm{h}$

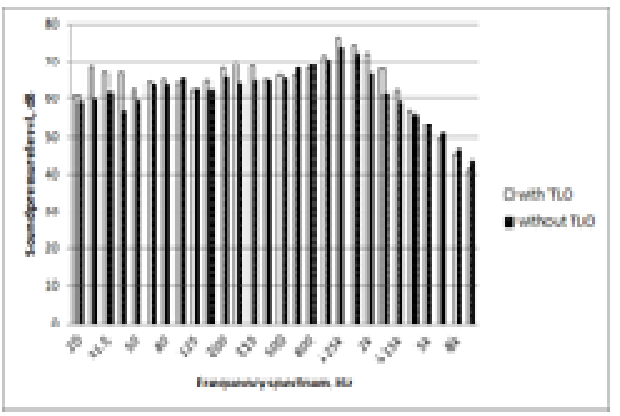

(d) $90 \mathrm{~km} / \mathrm{h}$

Fig. 8. Spectral frequency analysis of each vehicle's speed for roads with and without TLO

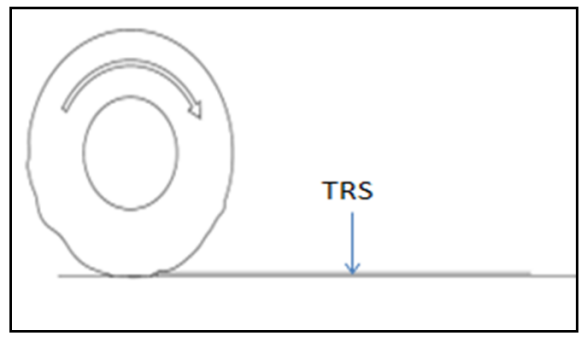

Fig. 9. Structural resonance - tire belt/carcass vibration

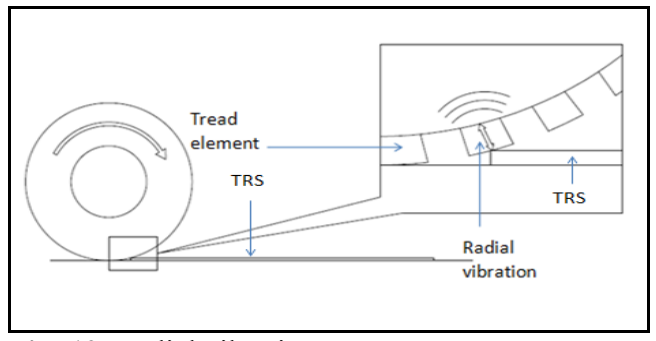

Fig. 10. Radial vibration

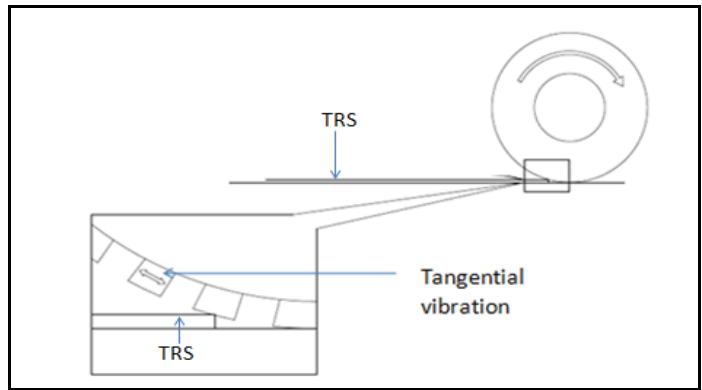

Fig. 11. Tangential vibration

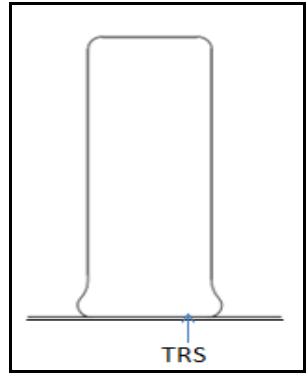

Fig. 12. Sidewall vibration

\section{Conclusion}

This study revealed the characteristics of the noise of tire-TRS interaction for two types of typical profile widely used in Malaysia. The results showed that the ten-raised-rumbler profile and three-layer-overlapped profile increased the noise level and have impulsive characteristics. The ten-raised-rumbler is capable of generating a relatively high noise at low speed, compared to the three-layer-overlapped system. Frequency spectral analysis showed that the ten-raised-rumbler profile produces a uniform increase in sound level for each octave band, and that the three-layer-overlapped profile has dominant noise at low level frequency, which is at about $<315 \mathrm{~Hz}$. Thus, the ten-raised-rumbler tends to irritate human ears. Based on this result and on the previous findings in the literature, the dominant generating mechanisms for the ten-raised-rumbler profile noise are tire tread vibration, surface texture vibration, 'air pumping', and slight structural resonance and sidewall vibration. Meanwhile for the three-layer-overlapped profile it is structural resonance, 
sidewall vibration and surface texture vibration. However, the mechanism is just anticipated speculation based on a comparison of spectral frequency with the previous literature. It should be noted that the frequency spectra for each mechanism is also influenced by tire design, tire pressure, and road design. These findings hopefully will provide a contribution to the development of a new approach in the manipulation of TRS profiles that can provide optimal auditory impact to road users without compromising the comfort of road users and generating excessive noise that may disturb surrounding localities.

This work is supported by the Fundamental Research Grant Scheme (FRGS-R.K130000.7840.4F653) financed by the Ministry of Education, Malaysia.

\section{References}

[1] D. Shinar, Traffic Safety and Human Behaviour, Elsevier, Amsterdam, (2007)

[2] W.K. Ng, P. Selva, OSH profile in the transport sector in particular commuting hazard, (2003), Retrieved 5 February 2011. from Malaysia Trade Union Congress: http://www.mtuc.org.my/osh_profile_transport.htm

[3] B.J. Katz, Peripheral Transverse Pavement Markings for Speed Control, PhD Thesis, Virginia Polytechnic Institute and State University, (2007)

[4] T.D. Thompson, M.W. Burris, P.J. Carlson, Speed changes due to transverse rumble strips on approaches to high-speed stop-controlled intersections, Transportation Research Record: Journal of the Transportation Research Board, 1973, 1-9, (2006)

[5] G. Bahar, T. Erwin, M. MacKay, A. Smiley, S. Tighe, Best Practice Guidelines for the Design and Application of Transverse Rumble Strips, Transportation Association of Canada, Ottawa, (2005)

[6] Ministry of Work, Traffic Calming Guidelines, Highway Planning Unit, Kuala Lumpur, (2002)

[7] C.A. Lopez, Pavement Marking Handbook, Texas Department of Transportation, Austin, (2004)

[8] P. Liu, J. Huang, W. Wang, C. Xu, Effects of transverse rumble strips on safety of pedestrian crosswalks on rural roads in China, Accident Analysis and Prevention, 43(6), 1947- 1954 (2011)

[9] H. Bendtsen, J. Haberl, U. Sandberg, G. Watts, SILVIA Deliverable 12: Traffic management and noise reducing pavements Recommendations on additional noise reducing measures, European Commission, Denmark, (2004)

[10] T. Yano, A. Kobayashi, Effects of duration of repeated impulsive sounds on noisiness, Environment International, 16(4-6), 547-554 (1990)

[11] B.S. Kim, G.J. Kim, L.T. Lee, The identification of sound generating mechanisms of tyres, Applied Acoustics, 68(1), 114-133 (2007)

[12] U. Sandberg, J.A. Ejsmont, Tyre/Road Noise Reference Book, INFORMEX Ejsmont and Sandberg Handelbolag, Kisa, (2002)

[13] J.S. Bolton, H.S. Kwon, Nearfield acoustical holography applied to sound radiation from tires, Purdue University, Indiana, (1998)

[14] R. Wayson, Relationship Between Pavement Surface Texture and Highway Traffic Noise- A Synthesis of Highway Practice, Transportation Research Board, Washington, (1998)

[15] W.V. Keulen, M. Duškov, Inventory study of basic knowledge on tyre/road noise, Road and Hydraulic Engineering Division of Rijkswaterstaat, Delft, (2005)

[16] ISO 13325, Tyres - Coast-by methods for measurement of tyre-to-road sound emission, International Organization for Standardization, Geneva, (2003) 
[17] M.J. Crocker, Theory of Sound - Predictions and Measurement, In M.J. Crocker (ed.) Handbook of Noise and Vibration Control, John Wiley, New Jersey, (2007)

[18] D.E. Karkle, M.J. Rys, E.R. Russell, Centerline rumble strips: Study of external noise, Journal of Transportation Engineering, 137(5), 311-318 (2011)

[19] J. Perisse, A study of radial vibrations of rolling tyre for the road noise characterisation, Mechanical Systems and Signal Processing, 16(6), 1043-1058 (2002) 